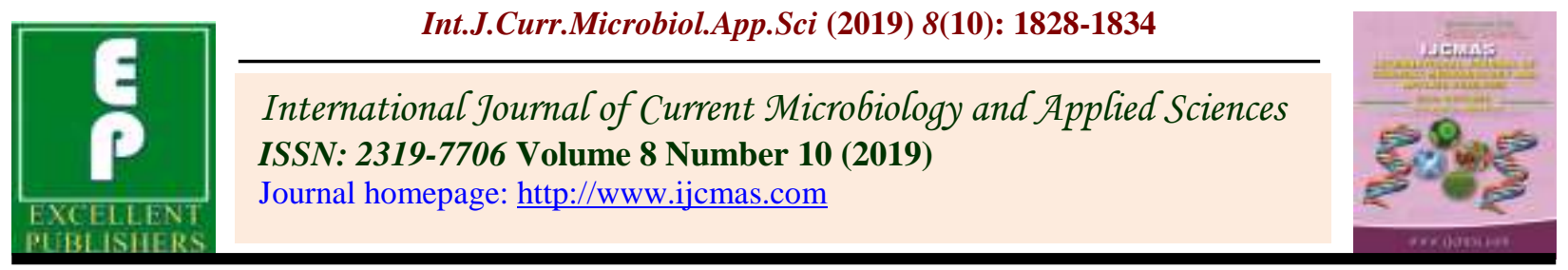

Original Research Article

https://doi.org/10.20546/ijcmas.2019.810.212

\title{
Screening of Mustard Lines against Alternaria Blight and Optimization of Screening Time under Cool Humid Conditions of Bihar, India
}

\author{
Abhishek Kumar $^{1 *}$, Chanda Kushwaha ${ }^{1}$, Chandan Kishore ${ }^{2}$, \\ Subhashish Sarkhel ${ }^{1}$ and Ravi Shankar Singh ${ }^{2}$ \\ ${ }^{1}$ Department of Plant Pathology, Bihar Agricultural University, Sabour, \\ Bhagalpur-813210, India \\ ${ }^{2}$ Department of Plant Breeding and Genetics, Bihar Agricultural University, \\ Sabour, Bhagalpur-813210, India \\ *Corresponding author
}

\section{A B S T R A C T}

\section{Keywords}

Alternaria,

AUDPC, Brassica,

Genotype

Article Info

Accepted:

15 September 2019

Available Online:

10 October 2019
Considerable losses caused by Alternaria blight on the oilseed crop rapeseed-mustard annually caused by Alternaria brassicae and Alternaria brassicicola. The study was conducted with the aim to assess tolerant sources of mustard lines against dark spot and to ascertain the optimum time of screening against the disease in Bihar region. We screened 50 lines of mustard against Alternaria blight under natural incidence in the year 2015-16 and 2016-17 using Area Under Disease Progress Curve (AUDPC). Visual estimation of disease severity was taken into consideration which was rated as no spot $(0 \%)$ on the leaves to more than $50 \%$ spots on the leaves and the same was corresponded with the scale given by AICRP, 2011 ranging from 0 to 9. Germplasms showed moderate tolerance to high susceptibility. Based upon average AUDPC values for two years, 4 genotypes namely IC-399840, IC-312496, IC-342778 and IC-399802 showed lowest AUDPC values between 300-500 showing tolerance and 4 genotypes namely IC-426392, Varuna, IC264131 and IC-491566were found to be highly susceptible with AUDPC values of 9001100 to Alternaria blight. Disease response was recorded at three different time intervals in order to find out optimum time of screening of mustard lines against Alternaria blight. Results suggested that at around 76 DAS would be the optimum time for assessment of mustard lines against Alternaria blight. At this time period (76 DAS) the disease distribution among the germplasm lines screened were found to be normally distributed. The tolerant sources will be useful for selecting elite genotypes for managing Alternaria blight where mustard cultivation is prevalent as well as in breeding for improved genotypes against Alternaria blight.

\section{Introduction}

Rapeseed-mustard (Bassica juncea L) is an economically important oilseed crop of the world. In India, rapeseed-mustard is grown over in diverse agro climatic conditions ranging from north-eastern \& north-western hills to down plain area. It is second largest 
indigenous oilseed crop after groundnut contributing 32 percent of total oilseed production in India. Out of 63.09 million tons of estimated rapeseed-mustard produced over 37.00 million hectares' acreage with the productivity of $1850 \mathrm{~kg} / \mathrm{ha}$ in the world, in India rapeseed-mustard is cultivated in an area of 6.7 million hectares with a production of 7.90 million tons with productivity of 1188 $\mathrm{kg} / \mathrm{ha}$. In Bihar rapeseed mustard is cultivated in 0.648 million hectares leading to production of 0.435 million tons with a productivity of $700 \mathrm{~kg} / \mathrm{ha}$ (GOI, Ministry of Agriculture \& Farmers Welfare, State of Indian Agriculture 2015-16).

The development of high yielding varieties coupled with improved production technologies has led to considerable increase in the productivity of rapeseed-mustard in India during past decade. But despite of increase, the yield of oilseed brassicas in India are much below compared to the global average and it is not able to meet the edible oil requirement for country's vast population. Among different constraints in the production of rapeseed mustard, diseases are the most important limiting factors which restrict the cultivation and decrease the productivity of these crops. In Indian context, fungal diseases are rated as one of the most important factor contributing to yield losses in oilseed crops (Grover and Growthaman, 2003).

Rapeseed-mustard is exposed to various types of foliar diseases viz., white rust (Albugo candida), powdery mildew (Erysiphe cruciferarum), downy mildew (Peronospora parasitica) and Alternaria blight (Alternaria spp.). Among these, Alternaria blight caused by Alternaria brassicae (Berk) Sacc. and A. brassicicola (Schw.) has been reported from all the continents of the world causing severe economic yield loss (Meena et al., 2010). The disease occurs regularly in moderate to severe form, its infection generally occurs on leaves, stem and siliqua resulting in reduction in yield and seed quality of brassica crops (Saharan, 1992).

Host resistance is one of the important components of integrated disease management. Management through resistance is considered as the best strategy. Due to the unavailability of resistance sources control of Alternaria blight disease becomes difficult and requires frequent fungicidal spray. The regular appearance of this disease with no apparent resistance among the related varieties of Indian mustard warrants immediate attention for the control of the disease. Skoropad and Tewari (1977) reported that among the oilseed brassicas species, B. oleracea and B. rapa are susceptible to Alternaria blight. The resistant sources will be useful for selecting elite genotypes for disease resistant where rapeseed mustard is prevalent. In addition, the resistant genotypes can serve as a gene pool used in breeding program to develop new resistant genotypes. Keeping in view the economic value of the crop and extensive damages caused by Alternaria blight, the present study was undertaken.

\section{Materials and Methods}

Evaluation of 50 Brassica lines was carried out in the year 2015-16 and 2016-17. In the year 2016-17, additionally 32 lines were screened. Rapeseed-mustard genotypes were obtained from division of Plant Breeding and Genetics Bihar Agricultural University (BAU), Sabour, Bhagalpur, India and were raised in the farm of oilseed section, BAU, Sabour. The trial was flanked with susceptible check (Varuna) for build-up of large number of inoculums. Experiment field where rapeseed-mustard was grown during the year 2015-16 was used for the year 2016-17 investigation also. Date of sowing was in the first week of December in both years. The crop spacing was maintained $30 \times 10 \mathrm{~cm}$ 
following standard package of practices. The experiment was raised as row trial with 2 rows per genotype. Each row length was 5 meters. Susceptible check Varuna was raised after each genotype. Randomly five plants from each genotype was selected and tagged for recording the appearance of disease symptoms and per cent disease severity at 7-day interval, 5 consecutive times based on visual observation (Fig. 1). Based on disease severity taken at different time interval, AUDPC was calculated. AUDPC was calculated by using following formula:

$A=\sum_{i=1}^{k} 1 / 2(\mathrm{Si}+\mathrm{Si}-1) d$

Where $\mathrm{Si}=$ Disease incidence at the end of the week $\mathrm{i}, \mathrm{k}=$ Number of successive evaluations of disease, and $\mathrm{d}=$ Interval between two evaluations.

Visual estimation of disease on all the 82 genotypes were made at three different time viz., 69 DAS, 76 DAS and 83 DAS to observe the distribution of Alternaria blight disease in the population of mustard over time. The data were analyzed statistically by using statistical tool completely randomized block design (CRD), one factor anova and average as per requirement. The treatments were compared by means of Least Square Difference (LSD) at $(\mathrm{P}=0.01)$ level of significance.

\section{Results and Discussion}

Reaction of Brassica genotypes to Alternaria blight under natural incidence during 2015-16 and 2016-17

Evaluation of 50 genotypes of mustard against Alternaria blight was carried using AUDPC to find out the most tolerant genotypes. None of the genotypes screened against Alternaria blight in the years 2015-16 and 2016-17 were found to be free from the disease. Among the 50 germplasms evaluated in both the years; four lines namely IC-399840, IC-312496, IC342778, IC-399802 showed AUDPC value between 300-500 and could be referred to as tolerant genotypes to Alternaria blight and four lines namely IC-426392, Varuna, IC264131, IC-491566 showed AUDPC value between 900-1100 which can be inferred as highly susceptible lines (Figure 3). Such highly susceptible lines could be used as susceptible check in screening of diverse lines of mustard. Rest of the genotypes had AUDPC values ranging from 500-900.

Fifty-four lines/varieties were tested by Srivastva et al., (2001) in an Alternaria sick plot and observed that none of the varieties were resistant to Alternaria blight. Kumar et $a l$. , (2008) reported partial resistance in three genotypes of B. juncea viz. Kranti, PR-8988 and PR-9024. Kolte et al., (2008) also reported B. juncea strains EC-399296, EC399299, EC-399301 and EC-399313 have shown tolerance to Alternaria blight. Singh et al., (2009) screened 81 lines of Indian mustard against Alternaria blight under natural epiphytotic conditions in Faizabad, India and reported that none of the genotype was completely free from visible symptoms of the disease. Only YET-25 was fairly resistant, however, 10 lines were moderately resistant. All these above reports support our findings. It can be concluded that use of germplasm which showed tolerance to Alternaria blight during the present studies can be utilized in future resistance breeding program to evolve tolerant lines of mustard with improved yield as well as quality of yield.

Optimization of screening time for the screening of mustard genotypes against Alternaria blight

Frequency distribution curve of disease severity of total of 82 germplasms grown in the year 2016-17 was drawn at three different 
time after sowing viz., 69 DAS, 76 DAS and 83 DAS. Disease distribution at 76 days after sowing had shown normal distribution which means near around 76 DAS can be optimum date to screen the mustard germplasm against Alternaria blight. At an earlier date of assessment (69 DAS), 34 genotypes out of 82 genotypes screened represented low disease severity $(<30 \%)$. Similarly, at a later date of assessment (83 DAS) none of the 82 genotypes showed less than $30 \%$ disease severity (Table 1 and Figure 2).

Fig.1 Representative images of disease scoring pattern used to derive AUDPC
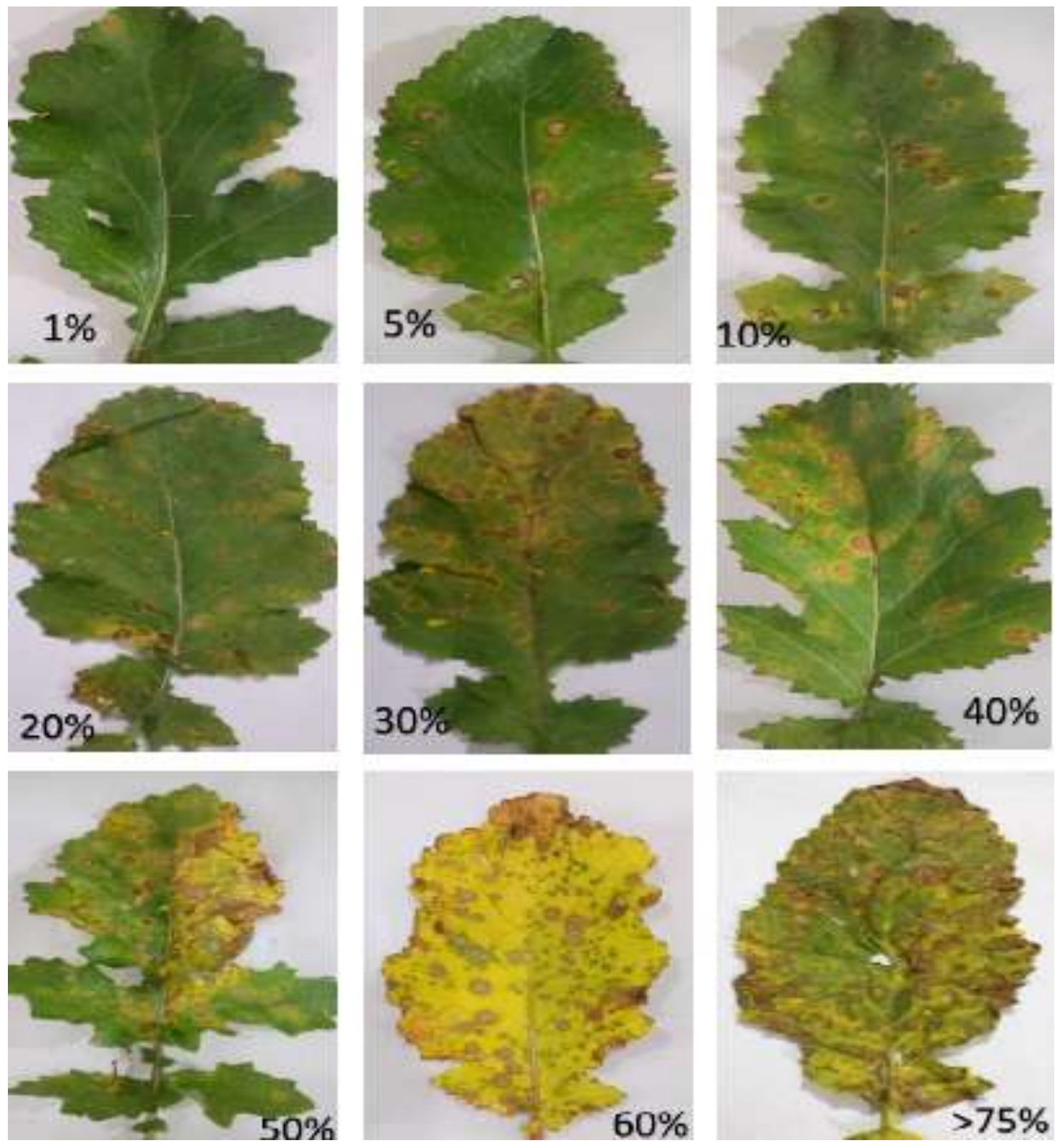
Fig.2 Frequency distribution of germplasms of mustard screened against Alternaria blight based on disease severity at different time intervals

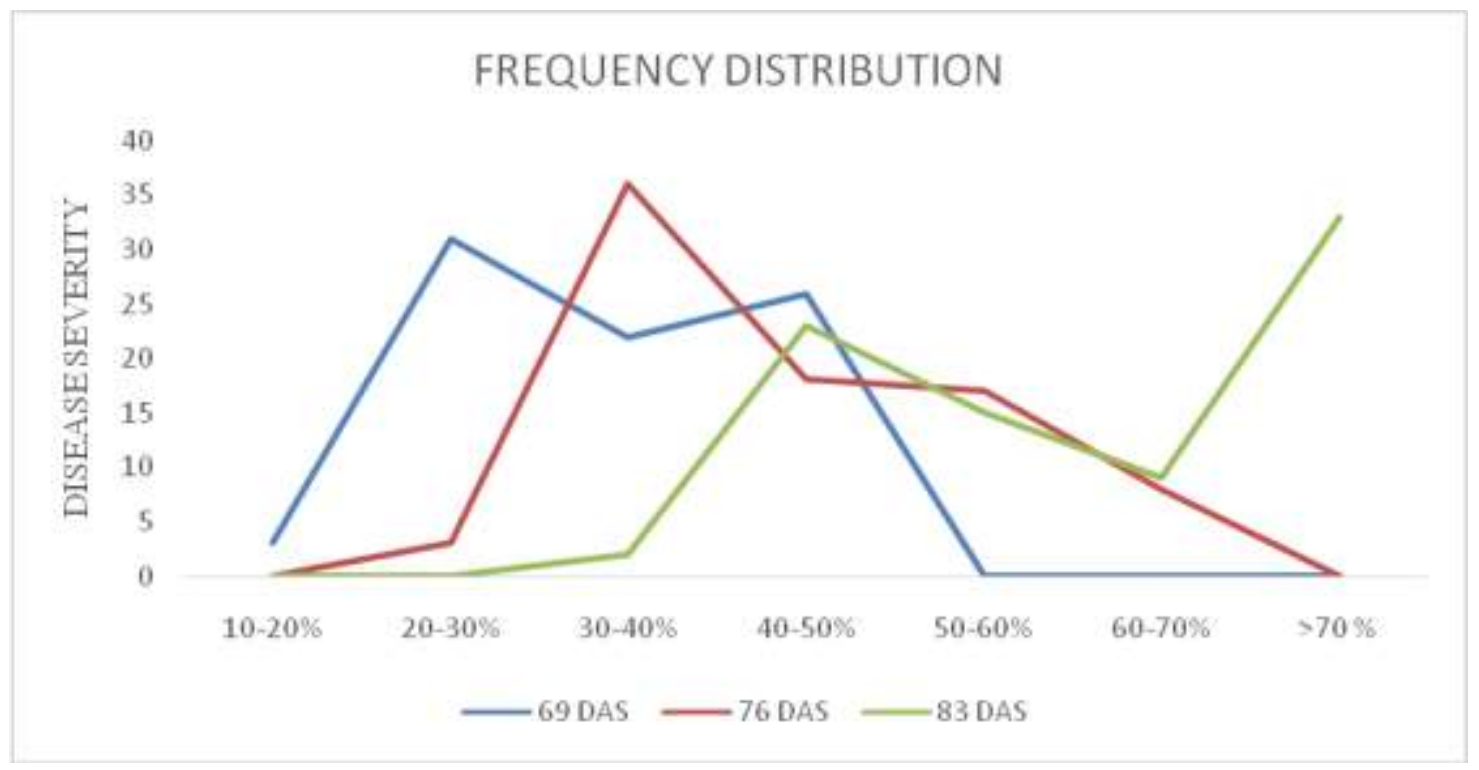

Fig.3 AUDPC value of 50 germplasms of mustard evaluated against Alternaria blight in the year 2015-16 and 2016-17

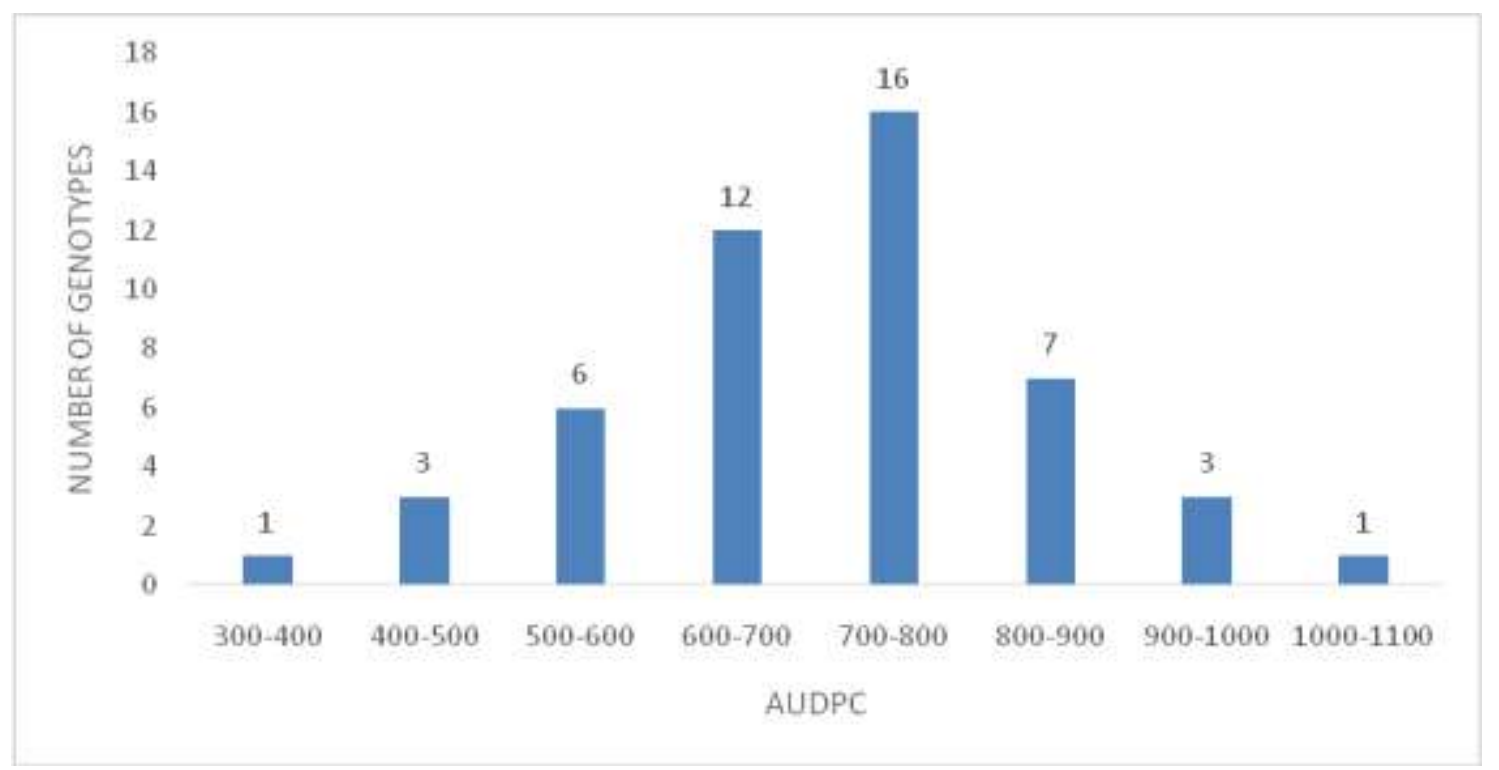


Table.1 Frequency distribution of germplasms of mustard screened against Alternaria blight based on disease severity at different time intervals

\begin{tabular}{|c|c|c|c|}
\hline \multirow{2}{*}{ Disease severity } & \multicolumn{4}{|c|}{ Number of genotypes } \\
\hline & 69 DAS & 76 DAS & 83 DAS \\
\hline $\mathbf{1 0 - 2 0 \%}$ & 3 & 0 & 0 \\
\hline $\mathbf{2 0 - 3 0 \%}$ & 31 & 3 & 0 \\
\hline $\mathbf{3 0 - 4 0 \%}$ & 22 & 36 & 2 \\
\hline $\mathbf{4 0 - 5 0 \%}$ & 26 & 18 & 23 \\
\hline $\mathbf{5 0 - 6 0 \%}$ & 0 & 17 & 15 \\
\hline $\mathbf{6 0 - 7 0 \%}$ & 0 & 8 & 9 \\
\hline $\mathbf{> 7 0} \%$ & 0 & 0 & 33 \\
\hline
\end{tabular}

Alternaria blight incidence shows a continuous distribution in the fields. Literature suggests that such disease response is greatly influenced by the environmental conditions (Humpherson-Jones, 1989). Based upon the frequency distribution of disease severity at different DAS (Table 1), it can be inferred that 76 DAS is optimum time for evaluation of germplasm of mustard against Alternaria blight since around 76 DAS the distribution is normal (Figure 2). At this period of time the genotypes were optimally differentiated based on disease response. It is likely that at an earlier $r$ date of evaluation i.e. before 76 DAS availability of inoculum would be a limiting factor. Similarly, when evaluating in the later dates, availability of healthy host tissue would become a limiting factor. Such observations were also observed in screening of slow rusting in pea (Kushwaha et al., 2007). The optimum time for evaluation of mustard genotypes thus characterized will help pathologist as well as breeder to screen the mustard crop more efficiently and will enable rapid progress in crop improvement program towards breeding for Alternaria bight tolerant lines.

\section{References}

Anonymous, India Rapeseed \& Mustard Crop Outlook 2015, Ministry of agriculture and Farmer Welfare, GOI.

Grover, A. and Growthaman, R. 2003. Strategies for development of fungusresistance transgenic plants. Current Sci., 84: 330-338.

Humpherson-Jones, F.M. 1989. Survival of Alternaria brassicae and Alternaria brassicicola on crop debris of oilseed rape and cabbage. Ann. Appl. Biol., 115: 45-50.

Kolte, S.J., Awasthi, R.P. and Vishwanath. 2000. Divya mustard: a useful source to create Alternaria black spot tolerant dwarf varieties of oilseed brassicas. $P l$. Varieties Seeds, 13: 107-111.

Kolte, S.J., Nashaat, N.I., Kumar, A., Awasthi, R.P. and Chouhan, J.S. 2008. Towards improving the genetic base of rapeseed-mustard through an Indo-UK research collaboration. Indian $\mathrm{J}$. of $\mathrm{Pl}$. Gen. Res., 21: 132-137.

Kumar, B. 2008. Assessment of slow blighting (Alternaria brassicae) resistance and yield in Indian mustard (Brassica juncea (L.) Czern \& Coss.). Indian Phytopath., 61: 171-183.

Kushwaha, C., Srivastava, C.P., Chand, R. and Singh, B.D. 2007. Identification and evaluation of a critical time for assessment of slow rusting in pea against Uromyces fabae. Field Crops Res., 103: 1-4. 
Meena, P.D., Awasthi, R.P., Chattopadhyay, C., Kolte, S.J. and Kumar, A. 2010. Alternaria blight: a chronic disease in rapeseed mustard. J. Oilseed Brassica, 1: 1-11.

Saharan, G.S. 1992. Disease resistance in breeding oilseeds brassicas. Narosa Pub. House, New Delhi, India: 181205.

Singh, H., Kaur, P., Kaur, P., Mukherjee, J. and Bal, S.K. 2009. Influence of meteorological parameters on the incidence and development of white rust and Alternaria blight in mustard (Brassica juncea L.) crop in the south- western region of Punjab. J. Agromet, 11: 135-142.

Skoropad, W.P. and Tewari, J.P. 1977. Field evaluation of the epicuticular wax in rapeseed and mustard in resistance to Alternaria brassicae. Can. J. Plant Sci., 57: 1001-1003.

Srivastava, M.P., Mehta, N., Sangwan, M.S. and Kumar, R. 2001. Evaluation of brassica varieties for resistance to Alternaria brassicae (Berk) Sacc. under epidemic conditions. Tests Agro: 22.

\section{How to cite this article:}

Abhishek Kumar, Chanda Kushwaha, Chandan Kishore, Subhashish Sarkhel and Ravi Shankar Singh. 2019. Screening of Mustard Lines against Alternaria Blight and Optimization of Screening Time under Cool Humid Conditions of Bihar, India. Int.J.Curr.Microbiol.App.Sci. 8(10): 1828-1834. doi: https://doi.org/10.20546/ijcmas.2019.810.212 